\title{
Driving with intelligent speed adaptation: Final results of the Belgian ISA-trial
}

\author{
Sven Vlassenroot ${ }^{\mathrm{a}, \mathrm{c}, *}$, Steven Broekx ${ }^{\mathrm{b}}$, Johan De Mol ${ }^{\mathrm{a}}$, Luc Int Panis ${ }^{\mathrm{b}}$, \\ Tom Brijs ${ }^{c}$, Geert Wets ${ }^{\mathrm{c}}$ \\ a Institute for Sustainable Mobility (IDM), Ghent University, Poel 16, 9000 Ghent, Belgium \\ ${ }^{\mathrm{b}}$ Flemish Institute for Technological Research (VITO), Boeretang 200, $2400 \mathrm{Mol}$, Belgium \\ ${ }^{\mathrm{c}}$ Transportation Research Institute (IMOB), Hasselt University, Wetenschapspark 5 bus 6, 3590 Diepenbeek, Belgium
}

Received 5 May 2006; accepted 22 May 2006

\begin{abstract}
In October 2002 the first ISA-trial in Belgium was started in Ghent. Thirty-four cars and three buses were equipped with the "active accelerator pedal". In this system a resistance in the accelerator is activated when the driver attempts to exceed the speed limit. If necessary, the driver can overrule the system. The main research goals of the trial in Ghent were to evaluate the effects of ISA on speed-change, traffic safety, drivers' attitude, behaviour and drivers' acceptance. To study these effects of the ISA-system both surveys and logged speed data were analyzed. In the surveys drivers noticed that the pedal assisted them well in upholding the speed limits and that the system increased driving comfort. Most important drawbacks were technical issues. Data analysis shows a reduction in the amount of speeding due to the ISA-system. There is however still a large remaining percentage of distance speeding, especially in low speed zones. Differences between drivers are large. For some drivers speeding even increases despite activation of the system. For less frequent speeders average driving speed almost always increases and for more frequent speeders average speed tends to decrease. With the system, less frequent speeders tend to accelerate faster towards the speed limit and drive exactly at the speed limit instead of safely below, which causes average speeds to go up.
\end{abstract}

(C) 2006 Elsevier Ltd. All rights reserved.

Keywords: Intelligent Transport Systems (ITS); Intelligent Speed Adaptation (ISA); Acceptance; Driving behaviour

\section{Introduction}

Excessive speed can be considered as a contributory factor in road accidents. Not only can it be the cause of accidents, it also defines the level of impact. Finch et al. (1994) declared that reducing speed with $1 \mathrm{~km} / \mathrm{h}$ can

\footnotetext{
${ }^{*}$ Corresponding author. Address: Institute for Sustainable Mobility (IDM), Ghent University, Poel 16, 9000 Ghent, Belgium. Tel.: + 32 926482 09; fax: + 3292648390 .

E-mail addresses: sven.vlassenroot@ugent.be (S. Vlassenroot), steven.broekx@vito.be (S. Broekx), johan.demol@ugent.be (J.D. Mol), luc.intpanis@vito.be (L.I. Panis), tom.brijs@uhasselt.be (T. Brijs), Geert.wets@uhasselt.be (G. Wets).
} 
lead to $3 \%$ less accidents risk. Inappropriate speed is involved in around one-third of the accidents resulting in vehicle occupant fatalities (ETSC, 1995).

In 2000, the European Union (2001) has set the ambitious target to reduce the number of fatal accidents by half before 2010. Many different European countries have therefore taken actions to increase road safety. One of these actions is the further development of intelligent transport systems that potentially have a significant role to play in road safety. Indeed, since Intelligent Speed Adaptation (ISA) is considered as a useful device to reduce inappropriate speed, it may contribute to increase road safety.

ISA is an intelligent in-vehicle transport system, which warns the driver about speeding discourages the driver from speeding or prevents the driver from exceeding the speed limit (Regan et al., 2002). Most ISA-devices are categorized into three types (ETSC, 2005) depending on how intervening (or permissive) they are. An informative or advisory system will only give the driver feedback with a visual or audio signal. A supportive or warning ISA system will intervene when the speed limit is overruled. For example, the pressure on the accelerator pedal will increase when the driver attempts to drive faster than the speed limit. A mandatory or intervening system will totally prevent the driver of exceeding the limit: these systems cannot be overruled by the driver.

Several trials are already held across Europe, with different types of ISA. In the Netherlands, a mandatory system has been used. The United Kingdom, instead, focussed on an advisory system (Carsten and Comte, 1997; Carsten and Fowkes, 2000). In Sweden, a range of different types of systems were tested in different cities (Vägverket, 2002). Special focus in Sweden was on the "active accelerator pedal" (Almqvist and Nygård, 1997). The same system is also used in the Belgian trial.

From October 2002 until January 2004, an ISA-trial has been held in the city of Ghent (Belgium). 34 cars and 3 buses were equipped with an ISA-system called the "active accelerator pedal". To study the effect of the ISA-system on speed-change, traffic safety, drivers' attitude, behaviour and drivers' acceptance, surveys and analyses of driving data were held. In this paper, the results of this trial will be reported.

\section{Background of the Ghent ISA-trial}

In this trial, a half-open or supportive ISA-system was used. This system is better known as the 'Active Accelerator Pedal (AAP) or 'Limit Advisor' manufactured by the Swedish company Imita. This system has a force feedback function, which is a mechanical resistance applied to the accelerator pedal as a distinct moveable pressure point.

The test area covered the city of Ghent, within the ring-road R4. All legislated speed limits (30, 50, 70 and $90 \mathrm{~km} / \mathrm{h}$ ) within this area were put on a digital map. Inside the test-area the system could not be switched off. Outside the test-area, the participants could choose to enter a speed limit manually to activate the system.

In total, 37 vehicles participated in the ISA-trial. Twenty vehicles were owned by private test-drivers, 17 vehicles were owned by companies: six cars of the City of Ghent (one of the Social Services), five vehicles of the Ghent University, three buses of the regional public transport company, two vehicles of the Province of East-Flanders and one of Volvocars Ghent.

To recruit private test-drivers, advertisements were published in different media. Possible candidates could respond by letter to receive an application form. Hundred and eight drivers were retained as potential candidates. The drivers were selected from those 108 applicants based on technical feasibility of installation of the system inside the car, gender and age. It was difficult to have equal age and gender groups because a low number of women had respond. Twenty candidates ere selected as test-drivers: 11 male and 9 female drivers. Also, not every selected driver was the only driver of the vehicle. The total number of voluntary drivers was 28 , spread over the 20 private cars.

Companies selected their cars themselves, only based on the given criteria of technical feasibility of installation. The gender and age of these test-drivers were not known in advance. By these selected cars it was assumed that there would be more than one driver, for example the bus drivers. The total (restricted) number of test drivers was 62: 42 male and 20 female spread over different ages. 


\section{Research goals and methodology}

The main research goals of the trial in Ghent were to evaluate the effects of ISA on speed-change, traffic safety, drivers' attitude, behaviour and drivers' acceptance. Two methodologies were used: (1) a behavioural study using questionnaires and (2) data-logging. The questionnaires were held once before driving with the AAP, during the trial (AAP active) and at the end of the trial. Data-logging was done during whole the trial.

\subsection{Measuring the carrying capacity}

How people think about mobility in relation to speed and excessive speed was a major issue of interest. It was considered that people's attitude about speed and speeding can have a main influence on their driving behaviour with ISA and, furthermore, in their acceptance of ISA. To determine these attitudes, a research method in a study carried out previously by the Belgian Road Safety Institute (BIVV) and the Centre of Sustainable Development/Ghent University was adopted (De Mol et al., 2001). This study measured the acceptance of ISA by the general public. The method denotes how people see mobility and transportation in relation with road safety, especially with respect to speed, speeding and speeding restrictions. This carrying capacity is based on the attitudes and opinions given by individuals, which stand for the general public. The concept determines several layers with mutual relations (see Fig. 1) and will be explained in more detail below.

\subsubsection{Socio-demographics and the use of transportation}

Socio-demographic issues and individual transportation habits are assumed to act as the 'basic' factors for the creation of a carrying capacity. These determinants will influence almost all the layers of the model.

\subsubsection{Basic attitudes}

Furthermore, it is assumed that driving behaviour is influenced by habits, rational decisions and emotional impulses (Levelt, 1998). Slotegraaf et al. (1997) declared that vehicles are not only a mode for transportation but also a way of expression with some symbolic sense: in this relation it can be seen as a manner of selfexpression and social positioning (status). In a certain way, attitudes also denote how people come to rational decisions. Behaviour in traffic is determined by the intentions people have, which are determined by the

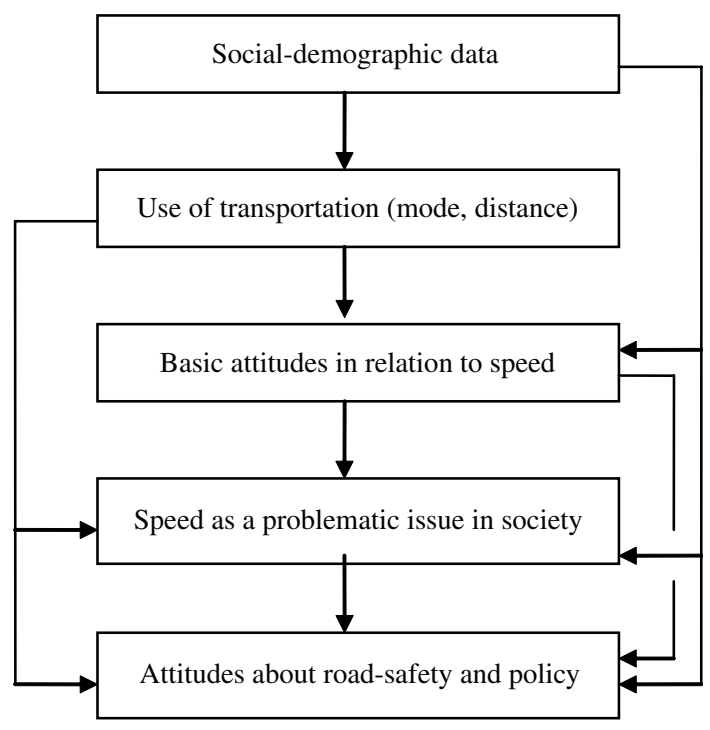

Fig. 1. Framework for measuring the carrying capacity. 
positions or attitudes that people have in traffic. In this study, attitudes must be seen as the positions taken by individuals about traffic and traffic safety issues.

The basic attitudes in this research denote how people see mobility and transportation, in particular the perception of speed in relation to motorised vehicles. The basic attitudes were: 'driving is only satisfying with a nice car'; 'speeding is exciting'; 'drivers have to be too aware of other road users'; 'if I drive, I live it up'; 'driving fast saves time'; 'a car is only for use of transportation'; 'driving fast is liberating'; 'people should be stimulated to use the car less'; 'driving fast is fun'.

\subsubsection{A problematic issue in society}

A social carrying capacity is also determined by 'being a (problematic) issue in society' (Molin and Timmermans, 1998). If there is no social indication that there is a problem about road safety, speed and speeding, future acceptance on ISA will be hard to achieve.

These indications are related to the actual situation on road categorisation and speed limits, and how people see their own behaviour on speed and speeding. Questions were posed about how people see the relation between road accidents and speed; in which conditions speed and speeding will be a problem; determination of speeding behaviour; and the feeling of insecurity.

\subsubsection{Attitudes about road safety and policy}

Some of the abstract norms and values are made concrete in issues concerning how people think about road safety measures. At this level, the 'real' discussion on possible acceptance will take place.

These 'layers' can be interpreted as sequential: the basic attitudes will determine how issues about speed and speeding will be notified as problematic and how people will experience the policy on road safety to handle the problem of speeding. For example: a driver, who describes his car as liberating and exciting and drives fast, will not recognise speeding as a problem. This driver will also not see measures taken against speeding as a priority or as being useful.

\subsection{Measuring the acceptance of the ISA-device}

Two major methods were used for measuring the acceptance of ISA. The first method was the procedure of Van der Laan et al. (1997). Acceptance is measured by direct attitudes towards a system and provides research with a system evaluation in two dimensions. The technique consists of nine rating-scale items. These items are mapped on two scales, a scale denoting the usefulness of the system, and a scale designating satisfaction. A second method was defining the voluntary use of the AAP. Outside the test-area the system could be activated manually (or voluntary). Both questionnaires as well as data-logging were held.

\subsection{Data-logging}

\subsubsection{Source data}

For this project all the vehicles were equipped with a data logger. The logging was started as soon as the ignition was turned on. The downloaded data were stored in a SQL-database for further analysis. To exclude incorrect loggings, a filter was applied on all fields. Due to these filters, $19 \%$ of all data was withdrawn. From around 99 million loggings, 80 million loggings are used for further analyses.

During the project several problems occurred related to the logging of the data: the system did not log according to the initial specifications. There was no logging of 'feedback active'. Therefore, it was not measured directly whether a feedback (pressure on the accelerator pedal when exceeding the speed limit) was provided to the driver. Also in the period before activating the ISA-system (26 October 2002) reference measurements were carried out to analyse the driver's behaviour in normal conditions. When analysing the first logged data, the data revealed that the speed measurements were not correct. This was due to the fact that before activating ISA, most of the loggings were done outside the ISA-zone, and therefore the speed logging was not correct. Because it was not possible to recover the data for the reference period, the demo had to be prolonged with a reference period after the ISA-active period. In this additional period, the feedback of the accelerator pedal was deactivated but not the display of the speed limit. So in a way this resulted in an open 
ISA instead of a non-ISA reference. Therefore to describe the results of the logged data, the indications of 'AAP active' and 'AAP inactive' are used instead of 'ISA' or 'No ISA.' Also it must be considered that the drivers had experienced driving with the AAP, so for the time of deactivation, awareness of the implemented speed limits; of driving the correct indicated speed limit could have been occurred.

These remarks should be kept in mind while reading the results of the logged data.

\subsubsection{Analysis of driving data}

Several studies have already been undertaken to study the behavioural impact of Intelligent Speed Adaptation systems (ISA). These studies have indicated the positive effects of ISA on speeding behaviour. However, how these effects are calculated varies significantly among studies. In Brookhuis and de Waard (1999) and Päätalo et al. (2001) average speeds and the number of made speed violations were analysed. In Päätalo et al. (2001) distinction has been made between overall driving speed and driving speed without stops, stops being defined as speeds below $1 \mathrm{~km} / \mathrm{h}$. Effects on speeding are examined by comparing the percentage of time that drivers speed. Average speeds for the Tilburg trial are calculated similarly (AVV, 2001). Data are however grouped for specific road sections. Besides average speeds, speed distributions and standard deviations were calculated to study the effect on driving behaviour.

Some studies only use a limited selection of logged data. For instance, data analysis for Spanish and Hungarian trials in the European PROSPER-project focuses on mid-block speed data (Hjälmdahl and Várhelyi, 2004; Várhelyi et al., 2005). This limits the analysis to top speeds. Using mid-block speeds, the effects of ISA are expected to be more significant compared with the analysis of complete data sets as lower speeds at, for example, intersections are not taken into account. Effects on acceleration behaviour below the speed limit are also not included. In Várhelyi et al. (2004) acceleration behaviour is looked into separately by analyzing data over a distance of $80 \mathrm{~m}$ before mid-block location. A selection of mid-block speeds implies that a choice has to be made on the locations to be analyzed. Which locations are selected could significantly influence the results. The risk of including logging errors or errors in speed maps is however limited.

In the European MASTER-project speeding behaviour on specific stretches was analyzed. For every $10 \mathrm{~m}$ along these stretches, logged speeds were recalculated by interpolating measured speeds on nearby locations (Várhelyi et al., 1998). By interpolating speeds to fixed locations, a bias towards slow speeds would be avoided. This bias can occur due to the fact that a higher number of loggings per metre are recorded at slow speeds compared with high speeds, causing slow speeds, which were logged more, to be weighted heavier in the calculations. A similar method was used to study the effects of an informative ISA-system in Denmark where the number of logs per meter is equated with a number of fictive log records (Madsen, 2002).

To study behavioural effects for the Ghent trial, the following parameters were examined: average speed, standard deviation, 85 percentile speed, percentage speeding and speed distribution. All data are included to avoid the impact of the choice of locations on the results. These parameters are calculated both time-based and distance-based. A time-based calculation signifies that all logged data are weighted equally. Time-based speeds are based on average speeds at which people travel per second. This means that zero speed $(0 \mathrm{~km} / \mathrm{h})$ is incorporated in the calculation of average speeds. These calculations are useful to estimate effects on travel time. Distance-based speeds are calculated based on average speeds at which people travel per metre. Idling is not incorporated in the calculation as no distance is covered and higher speeds are weighted more heavily in the calculation of averages as more distance is covered per second. A bias towards slow speeds is hereby avoided. Only distance-based results are reported in this paper.

\section{Results on the carrying capacity}

\subsection{Basic attitudes in relation to speed}

The results from the study indicate that ISA has a certain effect on the drivers' opinion on basic attitudes. Basically, most of the drivers did not think that driving fast is fun (average, more than $70 \%$ ), or exciting (average, more than 53\%). Their opinions about these issues did not change dramatically during or after the trial. More people agreed on 'driving fast is liberating' during (79\%) than before $(69 \%)$ or after $(71 \%)$ the trial. More than $75 \%$ did not agree with the attitude 'if I drive, I live it up', although this opinion increased (84\%) during 
the trial and decreased (74\%) afterwards. Before the trial, one out of five drivers agreed that 'driving fast saves time'. During the trial only $5 \%$ shared this opinion and after the trial, only one out of 10 thought that 'driving fast saves time'. Before $(84 \%)$, during $(82 \%)$ and after $(86 \%)$ the test, a huge majority agreed that 'people should be stimulated to use the car less' and that 'a car is only a way of transportation' (around 70\%). Before the trial, $38 \%$ thought that 'driving is only satisfying in a nice car'. During the test, most of them $(43 \%)$ were neutral, while after the trial most did not agree.

\subsection{Speed and speeding as a problem}

The attitudes on speed and speeding were analysed before, during and after the trial. The following possible attitudes were given to the test-drivers: 'speeding is dangerous'; 'speeding is sportive'; 'speeding is reckless'; 'speeding causes the most traffic accidents'. Although their opinions changed during and after the trial, most of the drivers confirmed that speeding is 'dangerous', 'reckless' and 'not sportive'. The most remarkable changes were about their opinion of 'speeding causes the most traffic accidents': $74 \%$ were agree before, $69 \%$ during, and $56 \%$ after the trial.

The drivers were also asked if they felt safe or unsafe when they saw other cars driving too fast in different speed areas (see Fig. 2).

The respondents would never feel safe as a pedestrian in any speed area when other cars were driving too fast. The test-drivers felt the most insecure as a pedestrian in $30 \mathrm{~km} / \mathrm{h}$ area $(94 \%)$ and pedestrian areas $(90 \%)$. As drivers, $49 \%$ felt unsafe on highways, $70 \%$ in urban areas when they noticed other cars driving too fast. As cyclist, $87 \%$ felt unsafe in urban areas, $83 \%$ outside urban and $30 \mathrm{~km} / \mathrm{h}$ areas, and $79 \%$ in pedestrian areas.

\subsection{Road safety policy and measures taken against speeding}

The test-drivers were asked their opinion about the different speed limits in different areas. On average, more than $60 \%$ of the drivers declared before, during and after the trial that the speed limits are good in all areas. Remarkably, however, during and after the trial, more and more drivers claimed that speed limits in 30 -areas (23\% before, $36 \%$ during, $41 \%$ after) and pedestrian areas ( $82 \%$ before, $61 \%$ during, $51 \%$ after) are too low. The main reason was that with the AAP, they were forced to adhere to the speed limits in these areas. Most drivers said that 'driving 30 or $15 \mathrm{~km} / \mathrm{h}$ is too slow', although they did not want to declare that ' $30 \mathrm{~km} / \mathrm{h}$ areas and pedestrian areas are not useful for road safety'.

The test-drivers were asked two questions about measures taken against speeding: how important is it to take actions against speeding in different speed areas, and which methods are the most appropriate?

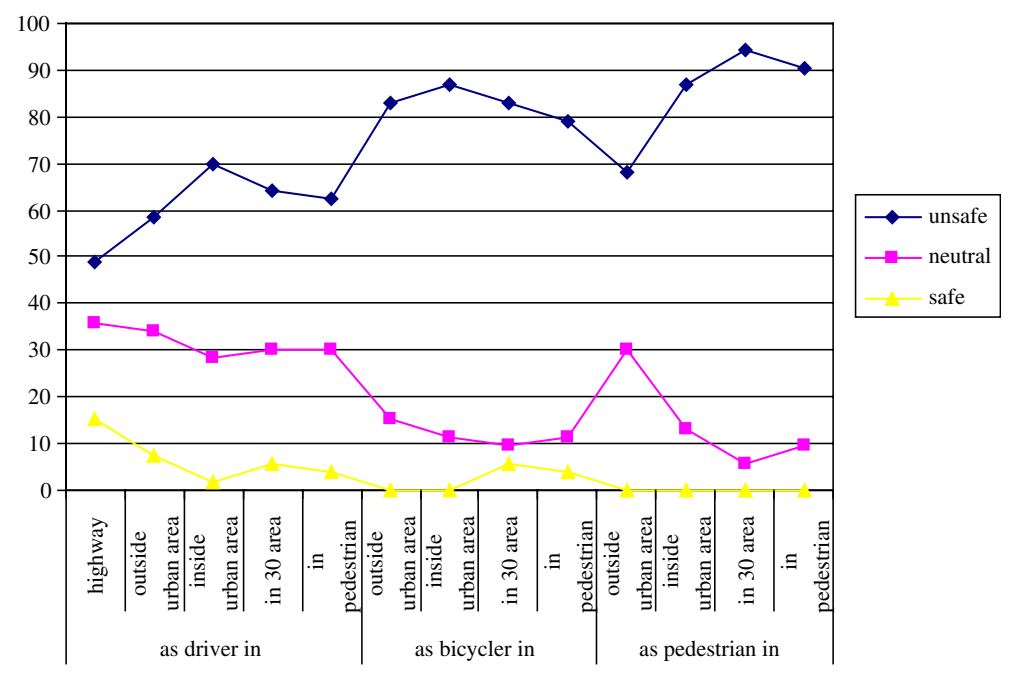

Fig. 2. Feeling of insecurity in different roles. 
The test-drivers declared that taking action against speeding is a priority in urban areas (53\%), followed by $30 \mathrm{~km} / \mathrm{h}$ zones $(51 \%)$, pedestrian areas (47\%), outside urban areas $(34 \%)$ and highways $(28 \%)$. However, the respondents argued that it is not important to take measures against speeding on highways. According to the respondents, they believed that the best methods taken against speeding are police controls and speed cameras, followed by speed bumps. Road safety campaigns were not believed to be effective.

\section{The drivers' acceptance of ISA}

\subsection{Acceptance scaled on usefulness and satisfaction}

All drivers (total) accepted the active accelerator pedal (see Fig. 3). After the trial, they experienced the pedal as being even more satisfying. The most pleased with the active accelerator pedal were the private drivers. During the project, they found it more useful but less satisfying than after the project. The most remarkable change is seen by the non-private drivers: while during the project they experienced it as not satisfying, although useful, they declared it was more satisfying and useful after the trial.

\subsection{Voluntary use of the AAP outside the test-area}

The drivers were also asked if they used the AAP manually (voluntary) outside the test-areas, and if so, on which roads. Mostly, it was used on highways (56\% during, $60 \%$ after) and outside urban areas (56\% during, $50 \%$ after), less in urban areas (46\% during, $41 \%$ after) or $30 \mathrm{~km} / \mathrm{h}$ roads (33\% during and after) outside the test area.

Additionally, the data-logging provides information on when drivers are outside the ISA-zone. However, no speed limits were available in these areas and the gas pedal was not activated. Drivers did however have the possibility to manually insert the speed limit into the system. This manual mode caused the active gas pedal to be operational. Whether the system was activated or not, was logged during the trial. The speed limit, which was inserted by the test-drivers, was however not recorded. Some drivers for instance stated in the survey to insert a speed of $130 \mathrm{~km} / \mathrm{h}$ on $120 \mathrm{~km} / \mathrm{h}$ roads to use the pedal as some kind of cruise control. Nevertheless, the percentage of loggings where the ISA system was manually activated is still a good indication of the willingness of people to use the system.

Results in Fig. 6 below show that in about 30\% of the time, a speed limit was manually inserted into the system. This percentage tends to increase as the trial continues. The percentage in month 7 is much lower than in other months: the holiday period and festivities in the city centre could explain this decline; for example

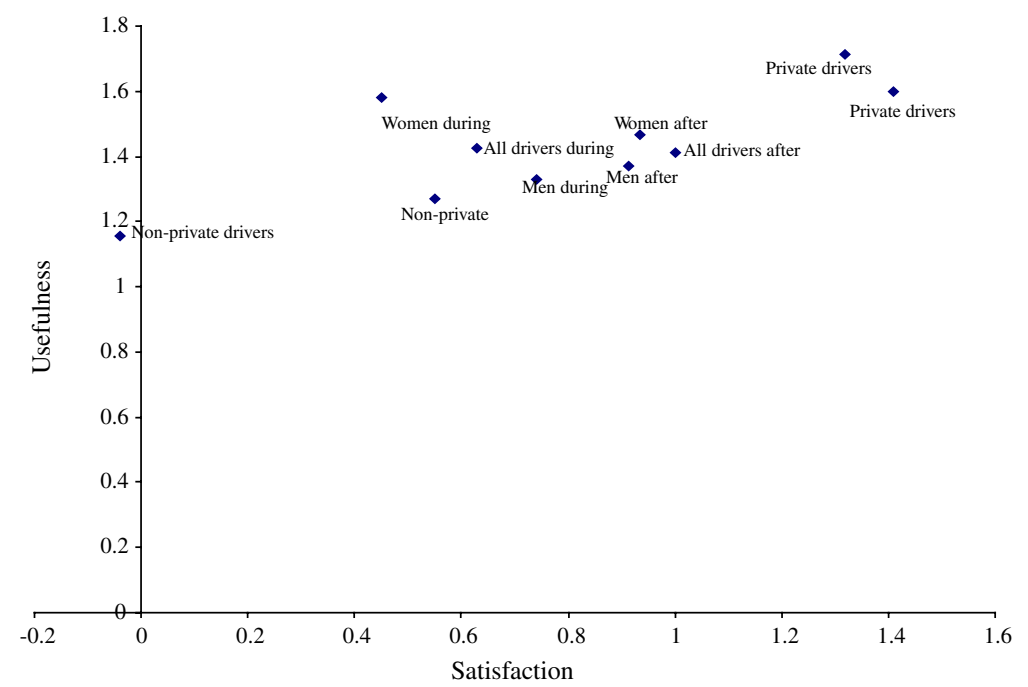

Fig. 3. Acceptance, scaled on usefulness and satisfaction of the active accelerator pedal. 


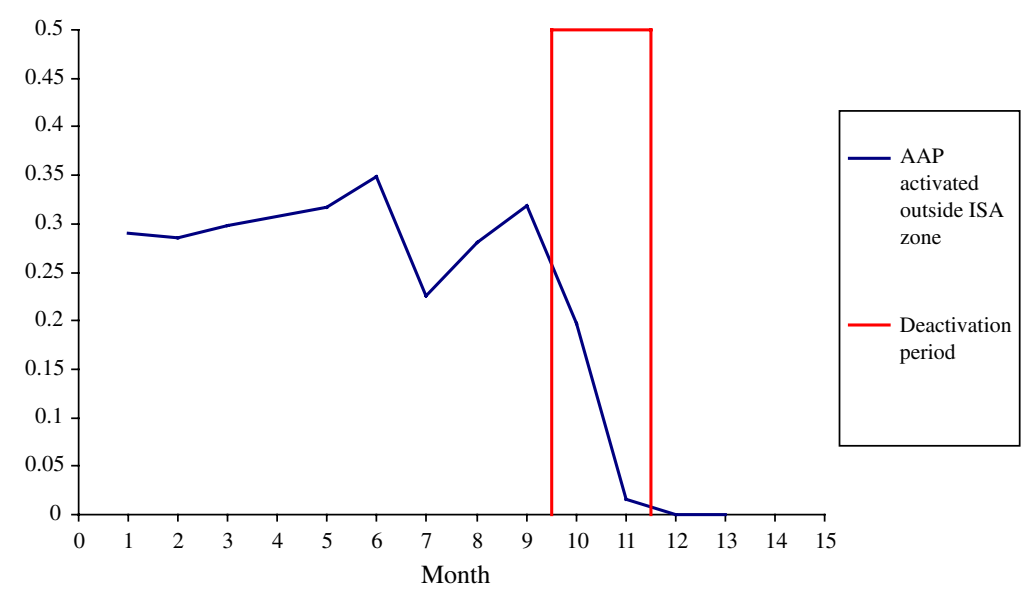

Fig. 4. Percentage of loggings outside ISA zone with AAP manually activated.

vehicles from organisations were used less. During the deactivation period, the system could not be manually used outside the area, therefore it must be noted that the strong drop in Fig. 4 during the deactivation period is only caused by the difference in time when the AAP in the cars were deactivated. This period started half September and ended half October.

At the end of the trial, the private test-drivers could choose to keep the ISA-system in their car. 15 private car holders chose to keep the system in the vehicle after the test-period, which is a significant indication that there is an acceptance of the active accelerator pedal. The main reasons given for keeping the system was that it was assisting, comfortable and provided relaxed driving.

\section{Driving behaviour with ISA}

To conclude, based on the questionnaires, we report the most remarkable experiences expressed by the drivers:

- Three out of five drivers declared that they drove more comfortably and relaxed than without ISA.

- One out of three drivers declared that they had more consideration for other road-users.

- The drivers looked less often at the speedometer and they let their foot 'rest' relatively often on the counterforce of the accelerator pedal, even as some of them tried to drive in such way that the pedal would not be activated.

- Most drivers did not notice any difference while driving with or without the active accelerator pedal with respect to looking at the speed signs, recognition of and involvement in certain traffic situations or keeping distance with other cars. If they experienced some changes it was more in favour of driving with ISA.

- One out of two test-drivers declared that they less overtook while driving with ISA.

- One out of two drivers found it easier to keep a constant speed with ISA.

- The ISA-system assisted them well to maintain the right speed. Certainly for upholding the $30 \mathrm{~km} / \mathrm{h}$ limit of which they noted that it was not an easy speed to drive at without assistance.

\section{Aggregated speeds}

The average speed $(V)$ indicated no significant difference between AAP inactive en AAP active (Table 1). Only at $90 \mathrm{~km} / \mathrm{h}$, the average speed decreased with $1.1 \mathrm{~km} / \mathrm{h}$. Ninety kilometer per hour zones were mostly rural roads and it was assumed that frequent speeding without ISA would happen more in these area. In $50 \mathrm{~km} / \mathrm{h}$ zones, where they drove the most, the average speed increased with $0.7 \mathrm{~km} / \mathrm{h}$. A possible explanation of this effect was that 'slow drivers'-drivers who would not exceed the speed limit, but would rather drive 
Table 1

Driving speeds average, standard deviation and 85 percentile of test area

\begin{tabular}{|c|c|c|c|c|c|c|c|c|c|c|}
\hline \multirow[t]{2}{*}{ Speed limit $(\mathrm{km} / \mathrm{h}]$} & \multirow[t]{2}{*}{ Kilometer driven } & \multicolumn{3}{|c|}{ AAP inactive } & \multicolumn{3}{|c|}{ AAP active } & \multicolumn{3}{|c|}{ Change in } \\
\hline & & $V$ & SD & V85 & $V$ & SD & V85 & $V$ & SD & V85 \\
\hline 30 & 5569 & 23.8 & 11.4 & 39 & 23.8 & 10.2 & 36.5 & 0 & -1.2 & -2.5 \\
\hline 50 & 95,509 & 30.9 & 14.9 & 49.9 & 31.6 & 14.6 & 49.6 & 0.7 & -0.2 & -0.4 \\
\hline 70 & 13,297 & 47.5 & 19.3 & 71.3 & 47.5 & 19.1 & 68.9 & 0 & -0.2 & -2.5 \\
\hline 90 & 17,194 & 69.1 & 19.3 & 89.4 & 68 & 17.6 & 86.9 & -1.1 & -1.7 & -2.5 \\
\hline
\end{tabular}

$V=$ mean speed, $\mathrm{SD}=$ standard deviation, $\mathrm{V} 85=85$ percentile.

under-were now driving more near the speed limit with the AAP. The V85 in the $50 \mathrm{~km} / \mathrm{h}$ zones, where the change in speed was noted minimal $(0.2 \mathrm{~km} / \mathrm{h})$ when driving with AAP, could also show the effect as described before. To compare the driving speeds with and without AAP, the V85 could give a better indication because extreme 'fast speeding' was eliminated. In 30,70 and $90 \mathrm{~km} / \mathrm{h}$ areas, the driving speeds decreased with $2.5 \mathrm{~km} /$ $\mathrm{h}$, which prove the effect of the active gas pedal. It must also be mentioned that the drivers were still driving to fast with the AAP in $30 \mathrm{~km} / \mathrm{h}$ areas. Some assumptions about driving behaviour in lower speed area are mentioned in the discussion/conclusion.

\section{Speeding behaviour}

\subsection{Perception of speeding behaviour}

Compared with their speeding behaviour before ISA, the test-drivers declared that they were driving less fast during the project (see Table 2). On highways, the answer on 'never speeding' increased during the project with $49 \%$, outside urban areas with $26 \%$, in urban areas with $16 \%$ and in 30 areas with $7 \%$. The answers on 'regularly speeding and mostly speeding' decreased on most categories during the trial. The answers given after the trial on 'never speeding' stayed level for outside urban areas, in urban areas and 30 roads.

\subsection{Speeding}

The percentage of the total amount of made speed violations of the test-drivers decreased when the active gas pedal was operational. Effects were largest in zones with the highest speed limit. Although speeding is reduced, there still remained a large percentage of speeding. Especially in the $30 \mathrm{~km} / \mathrm{h}$ zone the effect on

Table 2

Perception of speeding behaviour (in percentage)

\begin{tabular}{|c|c|c|c|c|c|c|c|c|c|c|c|c|}
\hline & \multicolumn{3}{|c|}{ Highway } & \multicolumn{3}{|c|}{ Outside urban area } & \multicolumn{3}{|c|}{ Inside urban area } & \multicolumn{3}{|c|}{ In 30 -area } \\
\hline & Before & During & After & Before & During & After & Before & During & After & Before & During & After \\
\hline Not known & 12.8 & 12.8 & 12.8 & & & & & & & & & \\
\hline Never & 12.8 & 51.3 & 28.2 & 38.5 & 64.1 & 56.4 & 35.9 & 51.3 & 51.3 & 38.5 & 43.1 & 43.6 \\
\hline Sometimes & 59 & 28.2 & 46.2 & 41 & 28.2 & 28.2 & 48.7 & 41 & 35.9 & 38.5 & 46.2 & 38.5 \\
\hline
\end{tabular}

Table 3

Percentage of distance speeding in test area

\begin{tabular}{lccc}
\hline Speed limit $(\mathrm{km} / \mathrm{h})$ & Kilometer driven & AAP inactive $(\%)$ & AAP active $(\%)$ \\
\hline 30 & 5569 & 45.90 & 42.80 \\
50 & 95,509 & 14.70 & 13.10 \\
70 & 13,297 & 17.60 & 12.60 \\
90 & 17,194 & 13.50 & 3.80 \\
Total & 131,569 & 16.30 & 13.10 \\
\hline
\end{tabular}




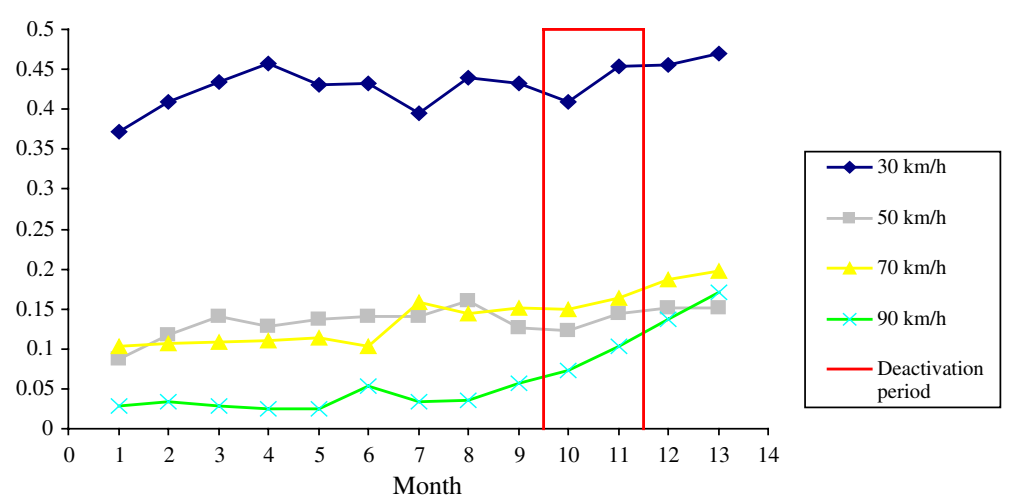

Fig. 5. Percentage of distance speeding on monthly basis for different speed zones.

speeding was minimal, although the amount of speeding was high. The counterforce, exerted by the pedal, was not strong enough to discourage drivers to exceed the speed limit (see Table 3).

\subsection{Evolution of speeding}

An important issue with making use of an active accelerator pedal was the applied counterforce. Speed offences can again become more frequent as drivers get used to the counterforce exerted by the pedal. To test this effect, loggings were compared on a monthly basis (see Fig. 5). Deactivation of the pedal took place for all cars during months 10 and 11. In these periods both loggings with and without the AAP-system activated were logged. After these months only loggings without the system were recorded.

In all speed zones, speed offences had increased in month 9, just before the start of the deactivation period, compared with the first month. In low speed zones speed offences increased rapidly the first three months and then staid more or less at the same level until deactivation. In high speed zones the increase was more gradually.

\subsection{Driver-specific analysis}

The effect of the AAP system on total speeding was already mentioned. Effects of the system were largest in $90 \mathrm{~km} / \mathrm{h}$ zone and lowest in the $50 \mathrm{~km} / \mathrm{h}$ zone. Speeding remained by far largest in the $30 \mathrm{~km} / \mathrm{h}$ zone. To study the effect on speeding more into detail, results are given per driver in the Figs. 6 and 7 below.

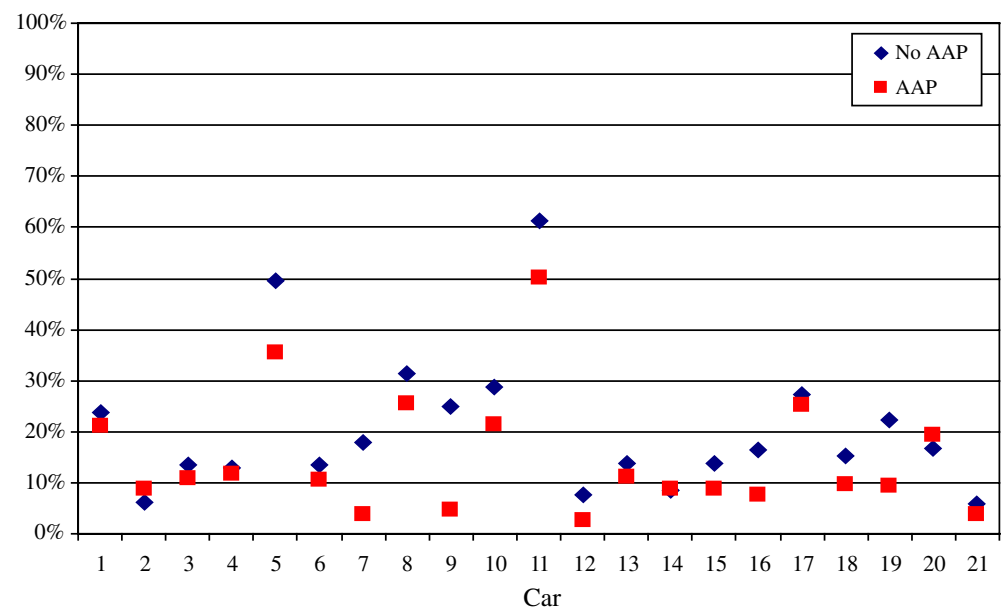

Fig. 6. Percentage of total distance speeding per car. 


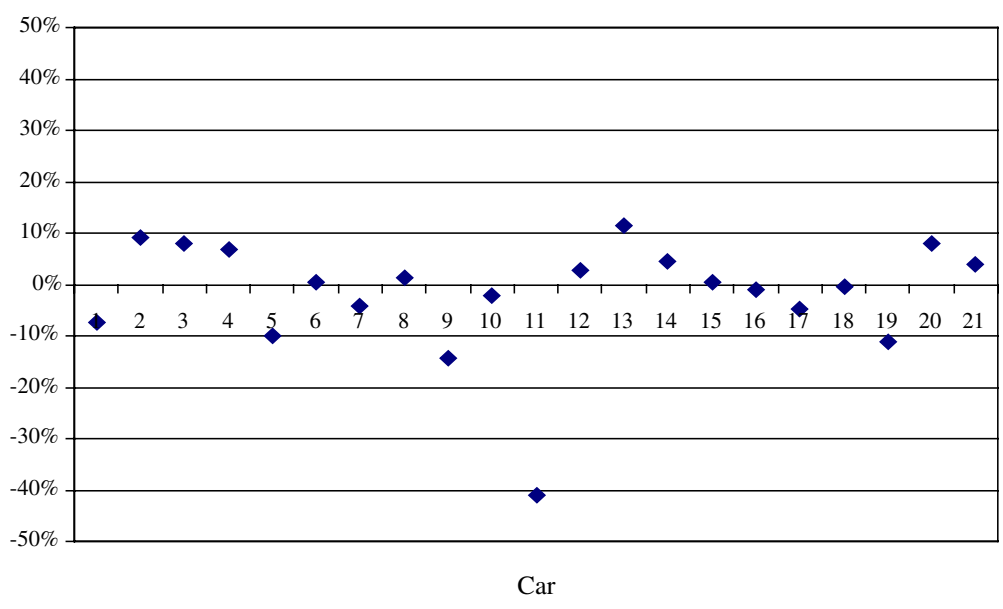

Fig. 7. Relative change of average driving speed due to activation of AAP system.

Differences between drivers were large. Distance speeding without the system varied between $6 \%$ and $61 \%$. With the system this varied between $3 \%$ and $50 \%$. For most drivers speeding reduced with the system. There are however three out of 21 cars for whom speeding even had increased (cars 2, 14 and 20).

Effects on average driving speed were also very diverse. For eight out of 21 vehicles the average driving speed increases. For less frequent speeders average driving speed almost always increased. Of the 10 least frequent speeders, nine had an increase in average speed due to activation of the AAP. For more frequent speeders average tended to increase. Of the 10 most frequent speeders, eight had an increase in average speed due to activation of the AAP.

\section{Conclusions/discussion}

Comparison of logged speed data during the activation period and speed data after this period showed that ISA had an effect on speeding. Effects were highest in the $90 \mathrm{~km} / \mathrm{h}$ zone where speeding decreased by almost $10 \%$. At lower speed limits effects were smaller although speeding was more frequent. In the $30 \mathrm{~km} / \mathrm{h}$ zone distance speeding decreased from $45.9 \%$ to $42.8 \%$, which means that the counter pressure was overridden in a vast amount of distance. Comparing effects on a monthly basis showed a higher amount of speeding at the end of the activation period than at the beginning. Especially in low speed zones speeding increased during the first months of usage.

Differences between drivers were however large. Distance speeding with the system varied between 3\% and $50 \%$. For most drivers speeding reduced with the system. Average speed of less frequent speeders tended to increase as drivers accelerated faster to the speed limit and drove exactly at the speed limit in stead of safely below. Average speed of more frequent speeders tended to decrease.

The aggregated speed effects even indicated that drivers with the AAP will drive closer towards the speed limit.

When questioning basic attitudes in the surveys, most of the drivers did not think that driving fast is fun, liberating or exciting, before, during or after the project. Most drivers declared that speeding is dangerous, reckless and not sportive. Driving with ISA changed their behaviour on speeding: during the project, most of the drivers declared that they never drove faster on highways, outside urban areas, in urban areas and 30-zones. The drivers used the system voluntary on highways and outside urban areas, which gave a first indication of their acceptance of the active accelerator pedal. They also experienced the pedal as satisfying and useful. After the trial, the private test-drivers could choose to keep the ISA-system in their car. Fifteen private car holders chose to keep the system in the vehicle after the test-period, which was a significant indication that there is an acceptance of the active accelerator pedal. The drivers noticed that the system assisted them well in upholding the speed limits and provided for comfortable and relaxed driving, although certain technical issues could be better. 
The drivers' perception on the effect of the system was evaluated more significant than the results from the logged speed data. Data logging problems could have influenced these results. The logged data were fully analyzed without making any distinction in road-characteristics. In this trial, the logged data was analyzed in total. In similar trials only stretches of roads were examined. The benefits are here that the research environment is controlled. Total analyses, like in this trial, make it possible to have a full picture of all the driving behaviour in the test-area.

Although the drivers declared that ISA is most useful in lower speed-areas, observed driving behaviour showed the opposite. It is assumed that different factors could have influenced the drivers. It is considered that factors, also described by Parker et al. (1992); Brown (2002) and Levelt (1998), like driving behaviour of other (non-ISA) drivers and discrepancy between the design of the road and the speed limit encouraged the test drivers to speed. These effects were not measured, but reports of some drivers could acknowledge this. Also these factors will not fully explain the speeding in lower $\mathrm{km} / \mathrm{h}$ zones.

As noted the less change in perception of their speeding behaviour in the questionnaires, the experience of 'driving slow' and the logged data could indicate that there is less acceptance of the $30 \mathrm{~km} / \mathrm{h}$ speed limit, although they also had declared to understand the benefits towards road safety of lower speed area. This effect of non-adaptation when even speed warning devices are used could be seen as disturbing for road safety measures. Lower speed limits like $30 \mathrm{~km} / \mathrm{h}$ (areas) are assumed to harmonise motorised with non-motorised traffic on an acceptable and safe manor in the benefit of all road users. Mostly this would indicate road infrastructure measures to support visualisation for the road users, limitation of passing motorised traffic, etc. (Broeckaert and De Mol, 2004). A lack of tradition, less sensitization and the sporadic coherence in implementation of lower speed areas led also to a general modest acceptance of $30 \mathrm{~km} / \mathrm{h}$ areas in Belgium. The driving behaviour of the ISA test-drivers must be placed in this context, certainly because during the project the $30 \mathrm{~km} / \mathrm{h}$ areas in Ghent increased significant. These results about the speeding behaviour must not be seen as indications about 'the failure' of $30 \mathrm{~km} / \mathrm{h}$ areas, but should be noted to give an impulse into future research about implementation, visualisation and acceptance of embedded speed limits.

As a final conclusion it can be noted that ISA can have benefits in road safety and could even open new debates about speed policies. In this trial ISA could be seen as a supportive system in road safety, but cannot be seen as the only manner to reduce speed violation. The use of ISA must also be geared to other road safety policies in reducing speed: better understanding of speed areas by drivers and better embedding of speed limits in relation with the use of the road should be considered.

As writing this paper, many initiatives on intelligent transport systems (ITS) and ISA are taken on European and national level: implementation strategies, research and initiatives on collecting speed limit data, legislation issues and better technical speed warning devices. At the other hand the discussion about ITS can open new debates about road safety measures taken today. ITS can support these measures but also will open the debate about new or to improve old policies. The main question can be asked how the general public, car manufactures and other actors will stand for these new devices and how they can be convinced to accept new legislation in relation to ITS. Future research on these topics would be considerate as a prior challenge about road safety and ITS.

\section{Acknowledgements}

The Belgian Project was made possible with the financial cooperation of the Belgium Institute for Road Safety, the city of Ghent, the insurance company DVV, the provincial administration of Eastern Flanders, Volvo-cars and the regional public transport company 'De Lijn'.

\section{References}

Almqvist, S., Nygård, M., 1997. Dynamic Speed Adaptation-Demonstration Trial with Speed Regulation in Built-up Area. Lund University, Sweden.

AVV, 2001. ISA Tilburg, eindrapportage praktijkproef intelligente snelheidsaanpassing. Ministerie van Verkeer en Waterstaat, Adviesdienst Verkeer en Vervoer AVV, Rotterdam.

Broeckaert, M., De Mol, J., 2004. Zone 30: veel meer dan een snelheidsbeperking. Naar $30 \mathrm{~km} /$ uur als algemene regel voor alle verblijfsgebieden. In Verkeersspecialist, 104. Wolters Kluwer, Mechelen. 
Brown, S.L., 2002. The relative effectiveness of self-reported deterrents to speeding. Road and Transport Research 11 (1), $43-51$.

Brookhuis, K., de Waard, D., 1999. Limiting speed, towards an intelligent speed adapter (ISA). Transportation Research, Part F 2 (2), 8190.

Carsten, O., Comte, S., 1997. UK work on automatic speed control. In: Proceedings of the International Cooperation on Theories and Concepts in Traffic safety Conference, Lund.

Carsten, O., Fowkes, M., 2000. External Vehicle Speed Control. Executive Summary of Project Results. University of Leeds, UK.

De Mol, J., Broeckaert, M., Van Hoorebeeck, B., Toebat, W., Pelckmans, J., 2001. Naar een draagvlak voor een voertuigtechnische snelheidsbeheersing binnen een intrinsiek veilige verkeersomgeving (towards a carrying capacity on in-vehicle speed warning devices within an intrinsic traffic environment). Centre for sustainable development/Ghent University—BIVV, Belgium.

ETSC, 1995. Reducing Traffic Injuries Resulting from Excess and Inappropriate speed. Brussels, Belgium.

ETSC, 2005. In-car Enforcement Technologies Today. Brussels, Belgium.

Finch, D.J., Kompfner, P., Lockwood, C.R., Maycock, G., 1994. Speed, Speed Limits and Accidents. Transport Research Laboratory (TRL), Crowthorne, Berkshire.

Hjälmdahl, M., Várhelyi, A., 2004. Speed regulation by in-car active accelerator pedal—effects on driver behaviour. Transportation Research, Part F 2 (7), 77-94.

Levelt, P., 1998. Speed and motivation: established and newly developed ideas about the content of questionnaires and the design of campaigns. Working Paper 2.2.1., MASTER, Brussels.

Madsen, J.R., 2002. Intelligent speed adaptation, an analysis of behavioural changes. In: Proceedings of E-safety: IT Solutions for Safety and Security in Intelligent Transport. International Congress \& Exhibition, Lyon.

Molin, E., Timmermans, L, 1998. De snelheid begrensd: Een empirisch onderzoek naar het draagvlak voor een Intelligente Snelheids Adapter voor personenauto's. Technische Universiteit Delft, Delft.

Päätalo, M., Peltola, H., Kallio, M., 2001. Intelligent speed adaptation-effect on driving behaviour. In: Proceedings of the European Working Group on Speed Control, Aalborg.

Parker, D., Manstead, A.S.R., Stradling, S.G., Reason, J.T., 1992. Intention to commit driving violations: an application of the theory of planned behaviour. Journal of Applied Psychology 77 (1), 94-101.

Regan, M., Young, K., Healy, D., Tierney, P., Connelly, K., 2002. Evaluating in-vehicle Intelligent Transport Systems: a case study. In: Proceedings of Road Safety Research, Policing and Education Conference, Adelaide.

Slotegraaf, G., Steg, E., Vlek, C., 1997. Diepere drijfveren van het autogebruik. Ontwikkeling en toepassing van een projectieve onderzoeksmethode voor het traceren van affectief-emotionele determinanten van het autogebruik. Rijksuniversiteit Groningen, The Netherlands.

Vägverket, 2002. Intelligen Speed Adaptation (ISA). Results of large-scale trials in Borlänge, Lidköping, Lund and Umeå during the period 1999-2002. Borlänge, Sweden.

Van der Laan, J.D., Heino, A., De Waard, D., 1997. A simple procedure for the assessment of acceptance of advanced transport telematics. Transportation Research-Part C: Emerging Technologies 5, 1-10.

Várhelyi, A., Comte, S, Mäkinen, T., 1998. Evaluation of in-car speed limiters, Final Report, Deliverable 11. MASTER, Brussels.

Várhelyi, A., Hjälmdahl, M., Hydén, C., Draskóczy, M., 2004. Effects of an active accelerator pedal on driver behaviour and traffic safety after long-term use in urban areas. Accident Analysis and Prevention (36), 729-737.

Várhelyi, A., Rook, A., Broekx, S., Int Panis, L., 2005a. Driver behavioural effects from ISA, Deliverable WP3. PROSPER, Brussels.

Várhelyi, A., Rook, A., Broekx, S., Int Panis, L., 2005b. Driver behavioural effects from ISA, Deliverable 3.4. PROSPER, Brussels. 